\title{
INJERTO DE EPITELIO GINGIVAL LIBRE: REPORTE DE UN CASO
}

\section{FREE GINGIVAL EPITHELIUM GRAFT: A CASE REPORT}

\author{
Ulises Peñaloza De La Torre \\ Gabriela Condori Condori ${ }^{2}$ \\ 1. Magister en Odontología. Docente de la \\ Universidad Nacional Jorge Basadre \\ Grohmann de Tacna. \\ 2. Cirujano Dentista. Consultorio privado.
}

\section{RESUMEN}

La encía adherida es fundamental para tener un buen pronóstico de los diferentes tratamientos odontológicos como son la ortodoncia, cirugía periodontal, implantología, entre otros. Es por ello que si el paciente no presenta suficiente encía adherida $(2 \mathrm{~mm}$ de longitud o un biotipo delgado), existen tratamientos para solucionar este problema como son las técnicas de injerto gingival libre, el cual constituye el gold standard para el aumento de encía queratinizada. El tejido conectivo obtenido con esta técnica es más superficial, además de denso y estable. Este procedimiento, se presenta como una alternativa en zonas donde hay demanda estética, ya que el color es similar a la del tejido donador, aunque la ganancia de tejido sea menor en relación a la técnica de injerto libre. El presente caso muestra el injerto de epitelio gingival libre, cuyo objetivo fue aumentar la longitud de encía adherida previo al tratamiento ortodoncico. La finalidad del procedimiento realizado fue de prevenir una recesión gingival. Es importante resaltar que el manejo quirúrgico fue fundamental para minimizar las molestias postquirúrgicas al paciente.

Palabras Claves: Biotipo gingival, encía queratinizada, injerto de epitelio gingival libre.

\section{ABSTRACT}

The adhered gum is essential to have a good prognosis of different dental treatments such as orthodontics, periodontal surgery, implantology, among others. That is why if the patient does not have enough gum ( $2 \mathrm{~mm}$ long or a thin biotype); there are treatments to solve this problem such as free gingival graft techniques, which is the gold standard for the increase of keratinized gum. The connective tissue obtained with this technique is more superficial, as well as dense and stable. This procedure is presented as an alternative in areas where there is aesthetic demand, since the color is similar to that of the donor tissue, although the gain of tissue is lower in relation to the free grafting technique. The present case shows the graft of free gingival epithelium, whose objective was to increase the length of gum, adhered prior to orthodontic treatment. The purpose of the procedure performed was to prevent gingival recession. It is important to emphasize that surgical management was fundamental to minimize post-surgical discomfort to the patient.

Keywords: Gingival biotypes, keratinized gum, free gingival epithelium graft. 


\section{INTRODUCCIÓN}

El injerto gingival libre pertenece a las técnicas de cirugía periodontal plástica. El término cirugía periodontal plástica surgió en el World Workshop in Periodontics en 1989 y englobaba aquellas técnicas destinadas a solucionar problemas relacionados con la encía, mucosa y hueso alveolar. Esto significó una evolución del término cirugía mucogingival descrito en 1957, y que lo definía como los procedimientos destinados a corregir problemas de encía insertada, vestíbulos superficiales e inserciones de frenillos. Este procedimiento forma parte de la terapia periodontal, cuyos objetivos son devolver el periodonto a un estado de salud controlando los factores etiológicos de la enfermedad periodontal, y reconstruir en lo posible las secuelas provocadas por la enfermedad ${ }^{(1)}$. El uso de injerto conectivo subepitelial condujo a un aumento estadísticamente significativo en el ancho de la encía queratinizada, cuyos efectos beneficiosos fueron la apariencia estética y la cicatrización del área donante por primera intención ${ }^{(2)}$, además de la reducción de la morbilidad posoperatoria. Por tanto, esta técnica es uno de los procedimientos preferidos en la cobertura de recesión ${ }^{(3)}$. Así, la técnica de injerto del tejido conjuntivo es el patrón oro donde hay demanda estética; en cambio, la técnica del injerto gingival libre es el patrón oro para el aumento de mucosa queratinizada en regiones en donde no hay demanda estética ${ }^{(4)}$.

El presente informe describe una técnica quirúrgica convencional de injerto de epitelio libre, con resultados predecibles y satisfactorios.

\section{REPORTE DE UN CASO}

Paciente de sexo masculino de 29 años de edad, según el sistema de clasificación de la American Society of Anesthesiologists (ASA) I. El paciente acude a consulta derivado de la especialidad de Ortodoncia.

\section{Examen clínico:}

Intraoralmente, se observa la pieza dentaria 13 con recesión gingival Miller clase $I^{(5)}$ con una encía insertada de $1 \mathrm{~mm}$ en vestibular, biotipo gingival fino ${ }^{(6)}$, movilidad dental grado I de Miller (Figura 1A).

\section{Examen Radiográfico:}

Radiográficamente, se observa la pieza dentaria $13 \mathrm{sin}$ alteraciones aparentes (Figura 1B).

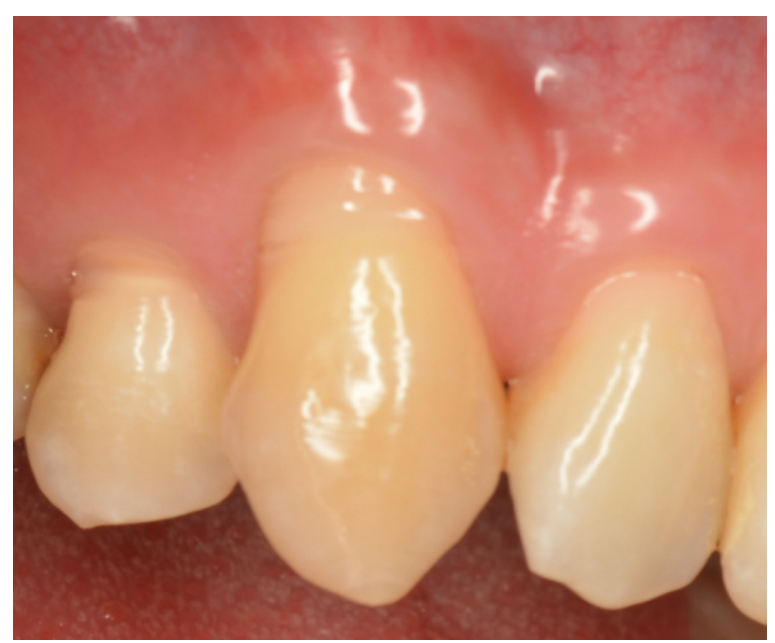

Figura 1. A. Preoperatorio



Figura 1. B. Radiografía periapical

Plan de tratamiento:

El plan de tratamiento va dirigido a producir la menor agresión posible con un mejor posoperatorio al paciente; aplicando técnicas que permitan mantener inmóvil el injerto, pues de esto depende que el injerto prenda en la zona receptora.

Zona dadora: Ubicada en la fibromucosa palatina entre distal y mesial del segundo premolar a $3 \mathrm{~mm}$ del margen gingival. Se realizó una incisión a espesor parcial con una hoja de bisturí $\mathrm{N}^{\circ} 15$ (Figura $1 \mathrm{C}, \mathrm{D}, \mathrm{E}$ ) mediante la técnica de injerto de epitelio-conectivo 
libre; luego de extraído el tejido epitelio-conectivo, se rellena la cavidad con una esponja de colágeno (Figura 1F) y coloca la placa de compresión palatina para controlar la hemorragia. La placa se extrae a partir del segundo día.

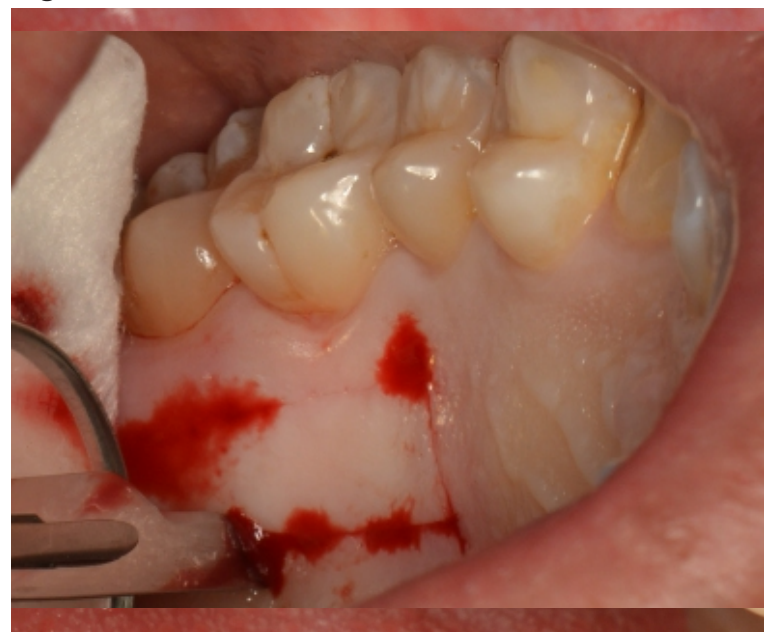

Figura 1. C. Incisión a espesor parcial

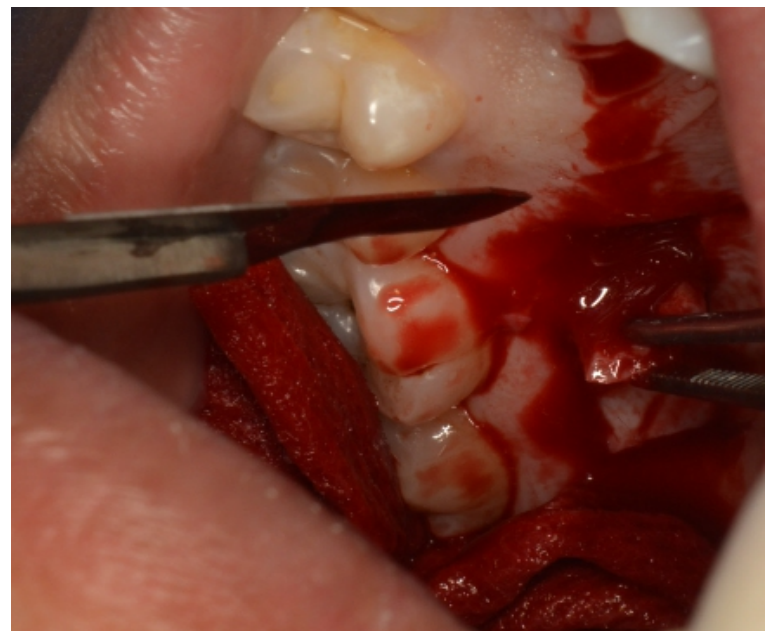

Figura 1. D. Decolorado

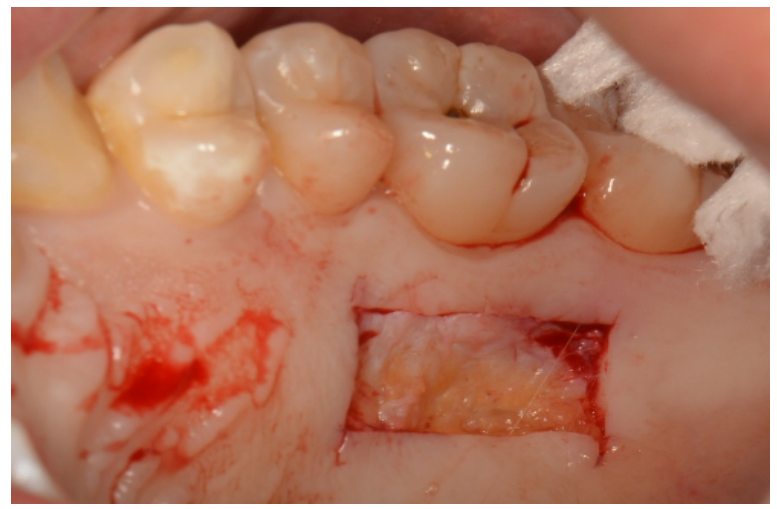

Figura 1. E. Zona donante

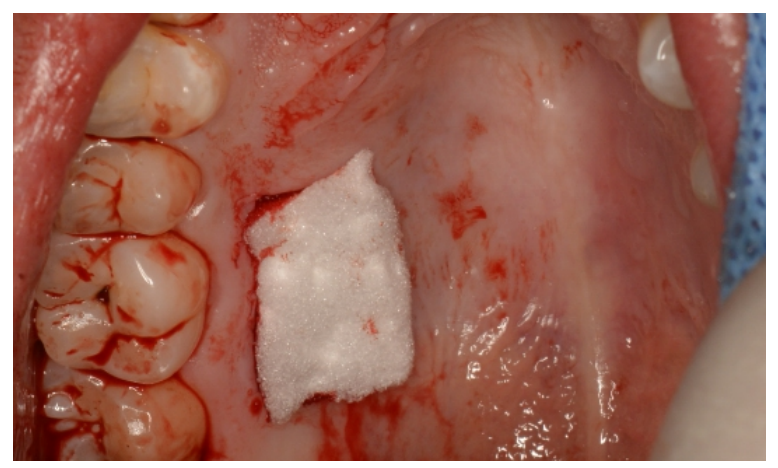

Figura 1. F. Apósito con esponja de colágeno

Zona receptora: Ubicada en vestibular de la pieza dentaria 13 , se realiza una incisión lineal con descargas a nivel de la encía adhería a espesor parcial de la misma longitud del injerto (Figura $1 \mathrm{G}$ ); se coloca el injerto de epitelio - conectivo (Figura $1 \mathrm{H}$ ) y se procede a suturar con ácido poliglicolico 5/0 mediante la técnica en ojal horizontales (cruzadas) y puntos simples (Figura 1I).

Se recomendó a la paciente una dieta blanda luego de la cirugía analgésicos y antiinflamatorios: Ketorolaco mas dexametasona vía intramuscular una dosis y luego diclofenaco mas paracetamol vía oral por 3 días.

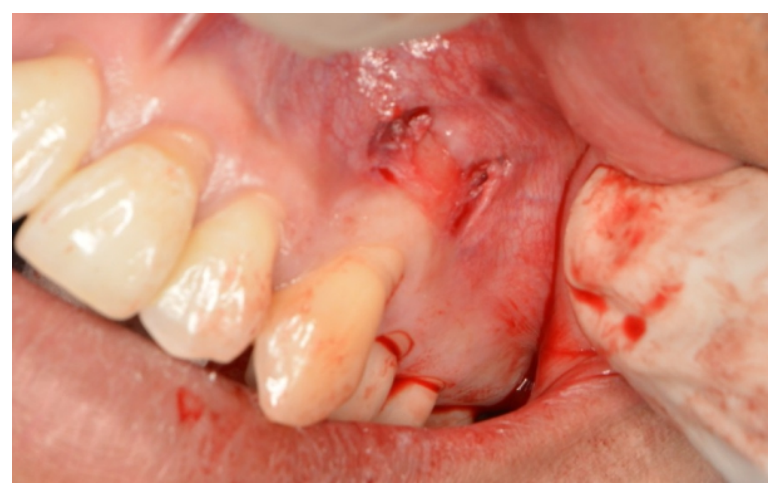

Figura 1. G. Zona receptora

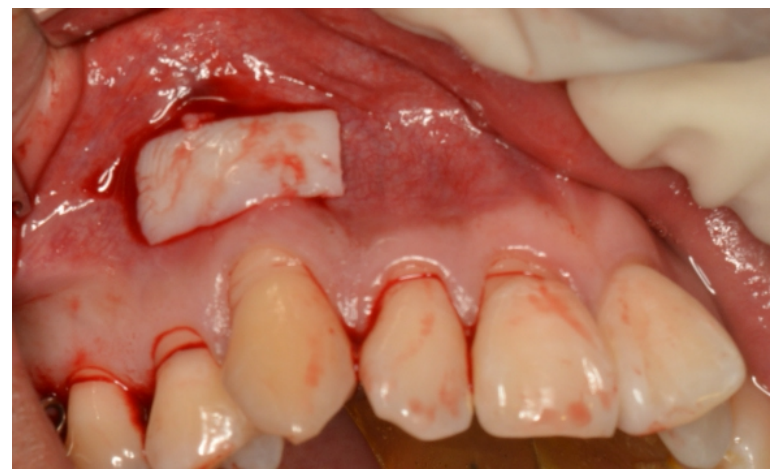

Figura 1. H. Posicionamiento del injerto 




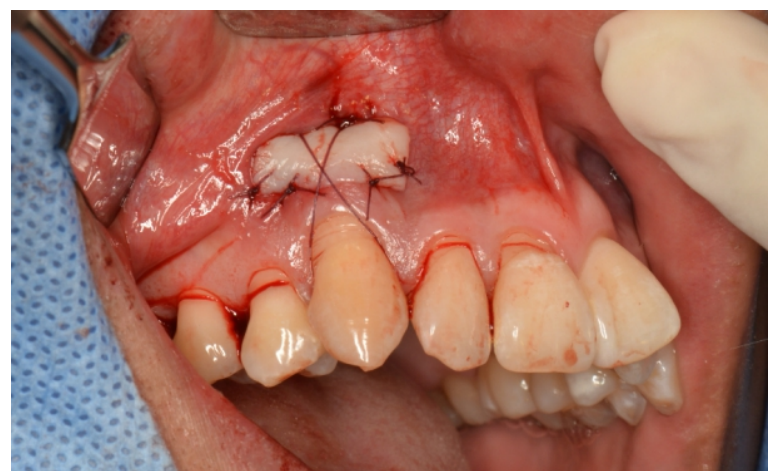

Figura 1. I. Fijación del injerto-sutura

\section{Seguimiento clínico}

Luego de 24 horas de posoperatorio, el paciente no presentó inflamación extraoral ni dolor. En la zona receptora, el injerto gingival esta inmovilizado por la sutura manifestándose la fase inicial de desepitelización (Figura 2 A). A los 6 días, el estrato blanquecino del injerto estaba en proceso de intercambio celular mostrándose un tejido rojizo liso, resultado del proceso de intercambio celular formado del tejido de granulación e inicio de la angiogénesis (Figura 2 B). A los 12 días, el injerto se encontraba en la fase inicial de reepitelización del tejido conjuntivo (Figura 2 C). A los 22 días, una vez terminado la fase de reepitelización, inicia la fase de queratinización (Figura 2 D). A los 30 días, termina la fase de queratinización mostrando características cromáticas iguales a la zona donadora (Figura 2 E). En la zona donadora a las 24 horas hay formación de coagulo (Figura 2 F). A los 6 días, se observa una superficie rojiza producto de la formación nueva de los vasos sanguíneos (Figura $2 \mathrm{G}$ ). A los 12 días, hay un relleno parcial de la cavidad por tejido epitelial neoformado (Figura $2 \mathrm{H}$ ). A los 22 días de control, se observa la formación epitelial inmadura (Figura 2 I). A los 30 días de control, se observa un epitelio más maduro, cuya coloración se va asemejando al epitelio circundante (Figura 3 ).

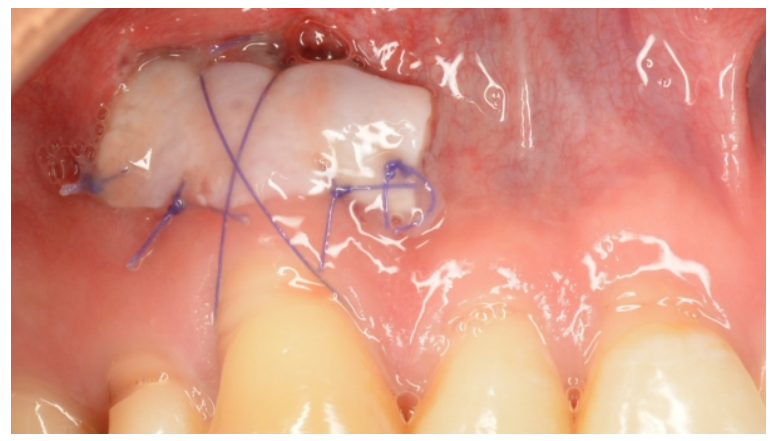

Figura 2. A. Zona receptora

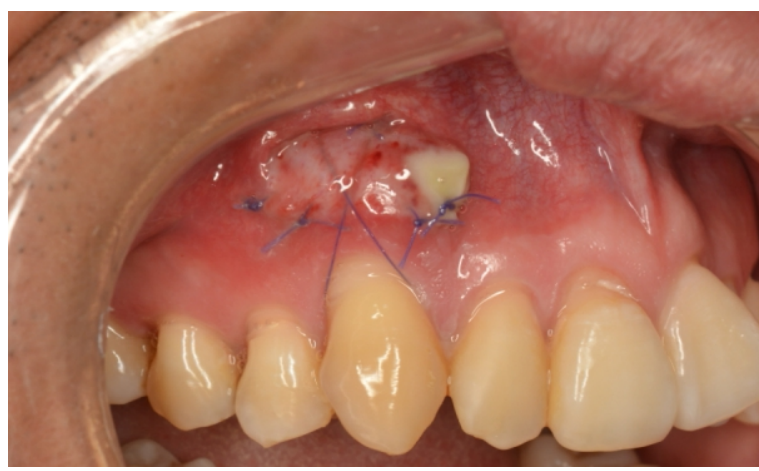

Figura 2. B. 6 días de control postquirúrgico

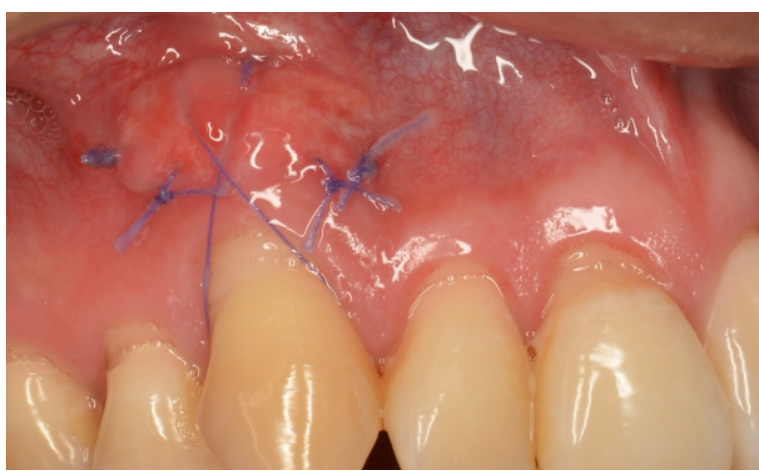

Figura 2. C. 12 días de control posquirúrgico

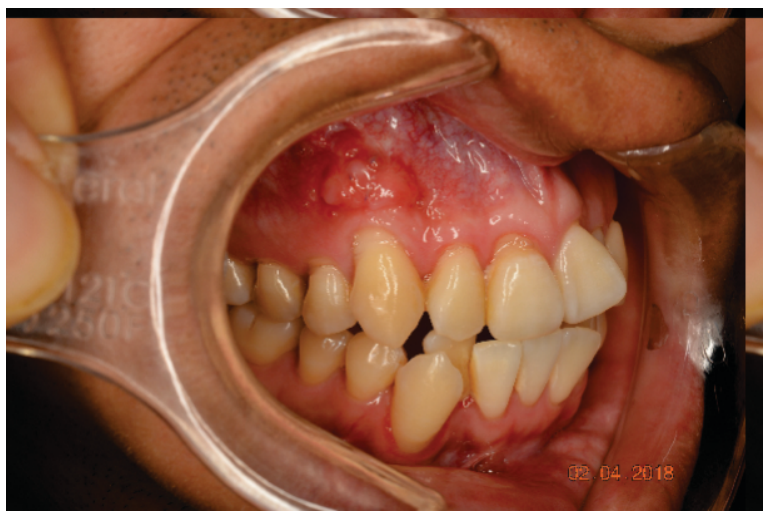

Figura 2. D. 22 días de control posquirúrgico

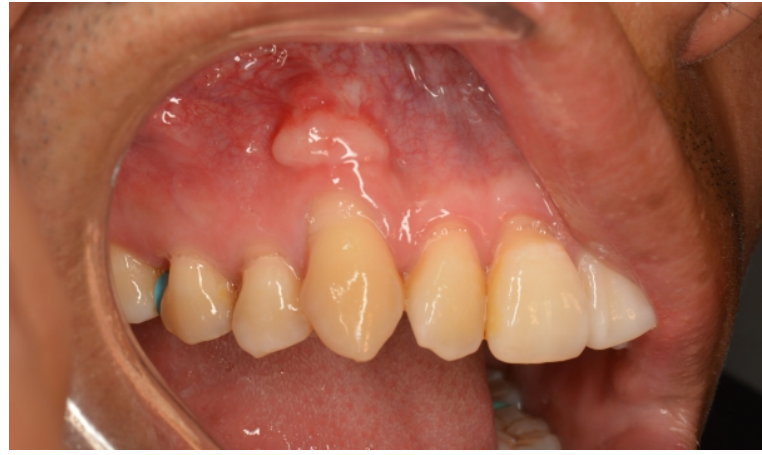

Figura 2. E. 30 días de control posquirúrgico 


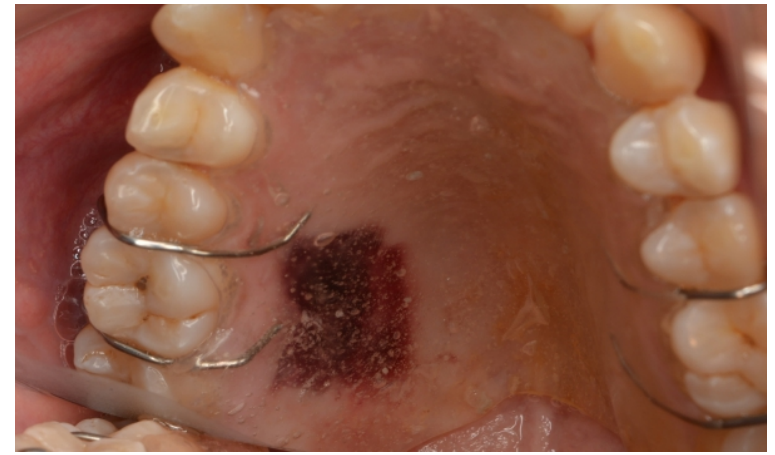

Figura 2. F. Zona donadora. 24 horas de control posquirúrgico

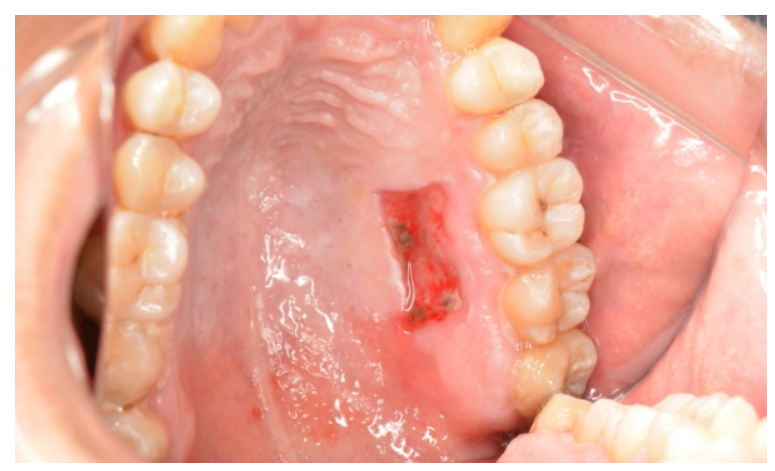

Figura 2. G. 6 días de control posquirúrgico

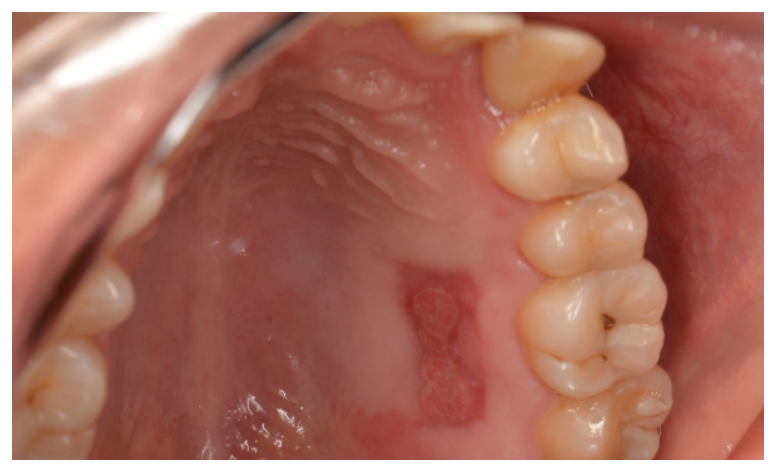

Figura 2. H. 12 días de control posquirúrgico

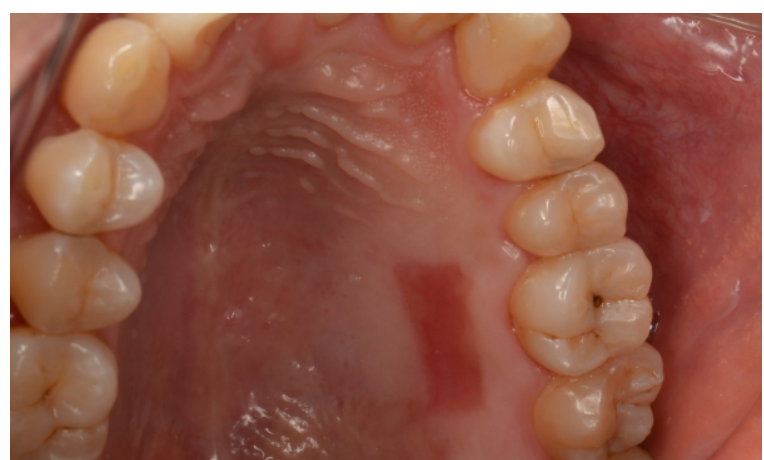

Figura 2. I. 22 días de control posquirúrgico

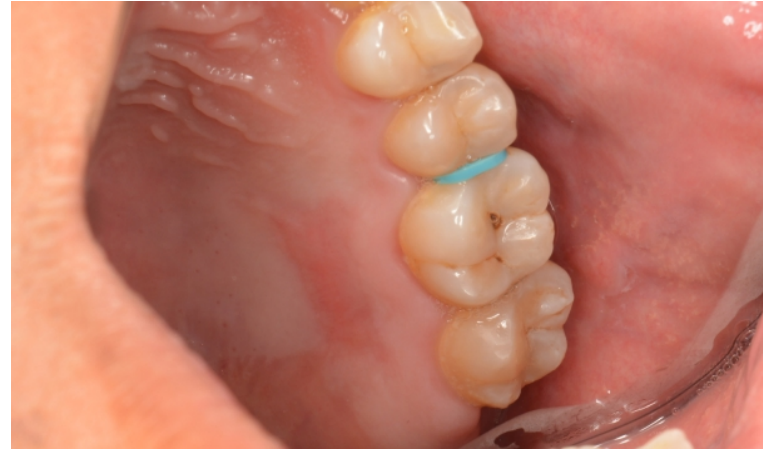

Figura 3. Zona donadora: 30 días de control posquirúrgico

\section{Discusión}

En el marco de los tratamientos ortodóncicos, las recesiones gingivales pueden aparecer siempre que ya exista una dehiscencia ósea vestibular, o bien cuando la propia ortodoncia saca el diente de su alveolo y lo desplaza hacia vestibular ${ }^{(7)}$, pero esto va relacionado al biotipo gingival. Un biotipo gingival delgado es menos resistente a la placa y a los ataques externos como los son las fuerzas ortodóncicas.

No existe consenso en la literatura, en cuanto a la cantidad de mucosa queratinizada necesaria para mantener una buena salud periodontal, aceptándose que es indispensable la presencia de una mínima cantidad, principalmente en áreas receptoras de prótesis o implantes ${ }^{(4)}$. Algunos autores proponen que el grosor del tejido no debe permitir la visualización por transparencia y su altura ser igual o mayor a $2 \mathrm{~mm}{ }^{(4)}$. Lang y col. (1972) demostraron que una franja menor a $2 \mathrm{~mm}$ puede favorecer la aparición de inflamación gingival con la posterior retracción gingival. Podemos intentar regenerar esas estructuras por medio de injertos homólogos (de epitelio o de tejido conectivo) o heterólogos (xenoinjertos) ${ }^{(4)}$.

La técnica de injerto gingival libre constituye el gold standard para el aumento de encía queratinizada en zonas que no hay demanda estética, dado que el color final es un blanco queloide similar al de la zona receptora. La técnica de injerto de tejido conectivo es una alternativa en zonas donde hay demanda estética; aunque la ganancia del espesor es menor en relación a la técnica de injerto libre. Por último, la cicatrización de las zonas donadora y receptoras tienen diferentes procesos fisiológicos, el tiempo y las molestias que esta presenta va depender de la técnica y el manejo posquirúrgico. En el presente caso, se extrajo un espesor mínimo de injerto de epitelio-conectivo, y se protegió la zona donadora de la injuria que pueda producir la alimentación del paciente. 


\section{REFERENCIAS BIBLIOGRÁFICAS}

1. Delgado J, Calvo J, Santos A. Injerto Gingival Libre. Revista Odontológica de especialidades. 2007. Volumen 57.

2. Duarte C. y cols. Injerto de tejido conjuntivo subepitelial. Consideraciones sobre la técnica. Revista Científica Dental Vol. 3, Núm. 3, Diciembre 2006. P. 183-191.

3. Uditi Jindal. Comparative evaluation of recession coverage with sub-epithelial connective tissue graft using macrosurgical and microsurgical approaches: A randomized split mouth study. Journal Indian Society of Periodontology. 2015 19(2): p. 203-207.
4. Moreira P. y cols. Alternativas para injertos epitelial y de tejido conjuntivo en Periodoncia - revisión de literatura. Actas Odontológicas. 2016. Volumen 12 (1) p. 39-44

5. Nagappa G. y cols. Classification systems for gingival recession and suggestion of a new classification system. Indian Journal of dental Research. 2018. Volumen: 29 (2). p. 233-237

6. Liu F. Pelekos G. The gingival biotype in a cohort of Chinese subjects with and without history of periodontal disease. Journal Periodontal Research. 2017. Volumen 52, Issue 6. P. 1004-1010.

7. Zucchelli G. Cirugía Estética Mucogingival. Volumen 2. Barcelona: Editorial Quintessence; 2014.

\section{Correspondencia}

Ulises Peñaloza De La Torre

E-mail: ulisespe@hotmail.com

Fecha de recepción: 07 de setiembre de 2018

Fecha de aceptación: 10 de marzo de 2019 